\title{
Between-trial transporting of animals: A methodological consideration
}

DONALD J. LEVIS, ${ }^{1}$ THE UNIVERSITY OF IOWA, lowa City, lowa 52240

The advantages of the one-way avoidance situation are numerous. However, to start a new trial, the $E$ is confronted with the additional problem of transporting $S$, usually by hand, from the nonshock compartment to the shock compartment. Two experiments were run in which the performance of a group transported between trials by hand was compared with a group transported by a specially designed box. The main finding in both experiments was that between-trial handling of $S s$ markedly retards the number of responses occurring during extinction. The importance of removing the handling variable from experiments was discussed.

Since Christie (1951) issued a warning about the potential contaminating effects of uncontrolled handling and gentling of animals, considerable data have accumulated to support this concern. Pretest handling has been demonstrated not only to have reinforcing properties (Candland et al, 1960; Candland et al, 1962; Sperling \& Valle, 1964) but also to affect the rat's weight (McClelland, 1956; Weininger et al, 1954), activity level (Weininger, 1956), and learning and retention ability (Barry, 1957; Bernstein, 1957).

Although control over the quantitative aspects of pretest handling is receiving more attention, considerably less concern for potential quantitative and qualitative effects of pre- and posttrial handling is apparent. Handling of Ss between trials occurred in over $35 \%$ of the studies reported in a recent unsystematically selected issue of the Journal of Comparative and Physiological Psychology (Vol. 69, No. 1, 1969). The obvious potential for experimental bias in such a situation should serve as sufficient incentive to find ways to eliminate this variable. Furthermore, some data have already been collected which suggest that between-trial handling, like pretest handling, also influences performance (Wahlsten et al, 1968; Wahlsten \& Sharp, 1969).

\section{EXPERIMENT 1}

Concerned with these problems, the present experiment was designed to compare the effects of manual between-trial transporting of Ss with a transporting procedure that eliminated handling. This comparison is made in the context of a one-way avoidance situation.

\section{Method}

Subjects. The Ss were 24 experimentally naive male hooded rats bred in the University of Iowa's Department of Psychology colony. The animals ranged in age from 98 to 113 days.

Apparatus The apparatus, a modified Mowrer-Miller one-way box, constructed of clear Plexiglas, was 36 in. long, 5 in. wide, and $10 \mathrm{in}$. high. The apparatus was divided into two equal compartments by a

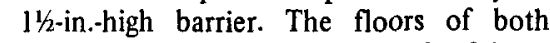
compartments were constructed of brass welding rods spaced $1 / 8$ in. apart, center to center. The Plexiglas tops of each compartment were designed so that they could be individually opened and closed. A 7-W, 24-V lamp, which provided a constant source of illumination, was mounted $8 \frac{1}{2}$ in. below the floor and $1 \frac{1 / 2}{2}$ in. in front of the apparatus, centered on its midpoint.

One compartment was designated the shock side and the other the nonshock side. One of two identical transport boxes was inserted into the nonshock compartment (see Fig. 1). Constructed of 1/8-in. clear Plexiglas, each transport box was 17 in. long, $4 \frac{1 / 2}{2}$ in. wide, and $91 / 2$ in. high, being slightly smaller than the inner dimensions of the apparatus. The top and one side of the transport box remained open. The open side of the transport box permitted $S$ to move from the shock side into the nonshock side. Such a response automatically placed $S$ inside the transport box. One edge of the floor was hinged to the side wall of the transport box, while the other side was held in place by a monofilament line that attached to a fastening stud mounted at the top of the box. The sides of the shock compartment and the sides of the transport box were covered on the outside with black paper. The grid floor of the nonshock compartment was also covered with black paper.

The CS-US sequence was initiated by a hand-operated microswitch. The shock US, which was delivered to the grid floor of the shock compartment, was produced by a Grason-Stadler grid scrambler shock source (Model E 1064GS). Once initiated, the CS-US sequence was controlled automatically by programming equipment. The control equipment was isolated from the apparatus, which was housed in a walk-in sound-attenuating IA chamber (Model 403). The closure of the hand-operated microswitch also started a Standard Electric stop-clock which indicated response latencies to the nearest 10 th of a second. A response by $\mathrm{S}$ (movement from the shock to the nonshock compartment) depressed the floor of the nonshock compartment, which engaged a microswitch and activated an electromagnet, the latter being designed to hold the floor stationary. Both the microswitch and electromagnet were mounted on the outside of the nonshock compartment. The intertrial interval was

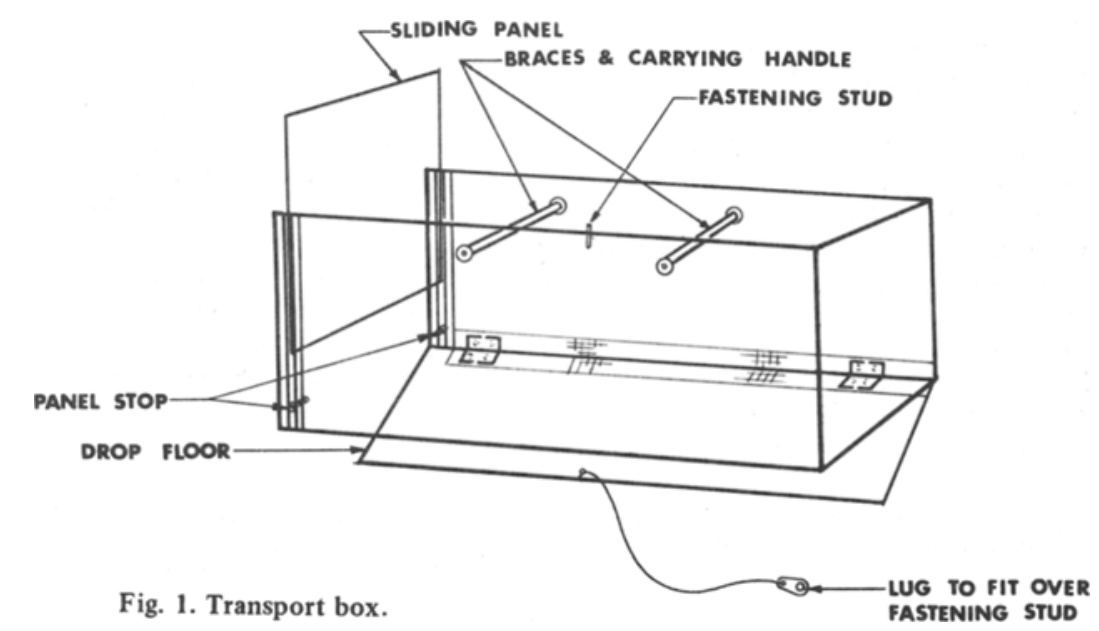


controlled by $\mathrm{E}$ who used a stopwatch. The time taken to transport $S$ from the nonshock to the shock compartment was also recorded. To achieve this, E pressed a footswitch when the lid of the nonshock compartment was opened to transport $S$. The footswitch controlled another Standard Electric stop-clock which stopped automatically when the switch starting the CS-US sequence was closed.

\section{Procedure}

All Ss were handled prior to the start of training trials for $12 \mathrm{~min}$ per day on each of 5 successive days in order to insure manageability of $\mathrm{Ss}$ assigned to the between-trial handled condition. The $\mathrm{E}$ wore gloves whenever contact was made with S. Following the completion of pretest handling, from 2 to 4 days of noncontact with $S$ preceded the start of training. Immediately prior to the start of the first training trial, each $\mathrm{S}$ was given a 5 -min adaptation period to each compartment of the apparatus. Ss were adapted to Compartment A first. A delayed conditioning procedure was used with a CS-US interval of $12 \mathrm{sec}$. The contextual cues of Compartment A served as the CS. The shock source that produced the US was set at $.8 \mathrm{~mA}$. A response was defined as movement from Compartment $\mathrm{A}$ to $\mathrm{B}$ that resulted in the depression of the activating leaf of the floor microswitch of Compartment B. This occurred when $S$ entered the transport box located inside Compartment B. Immediately following a response, E sealed off the open end of the transport box by inserting a sliding panel (see Fig. 1). An escape response from shock terminated both the CS and US, while a conditioned avoidance response (CAR) terminated the $\mathrm{CS}$ and prevented US onset. Each $S$ remained in Compartment B for a $45-\mathrm{sec}$ intertrial interval before being transferred back to the shock side. Acquisition trials were continued until $S$ reached a criterion of 10 successive avoidance responses, after which the shock was turned off. Extinction trials started on the next trial after the acquisition criterion was met and continued until $S$ had a latency greater than $30 \mathrm{sec}$ or after $S$ completed 200 trials with each trial latency under $30 \mathrm{sec}$.

Transport conditions. Twelve $S$ s were assigned to each of two groups. Assignment and order of running were determined randomly after Ss had been prehandled. Ss in Group H (handled) were transported between trials by being picked up in Compartment $B$ and placed on the grid floor of Compartment A. Group NH Ss (nonhandled) were transported by $\mathrm{E}$ between trials via the transport box. The transport box was picked up by the carrying handles, lifted out of

Table 1

Means and Standard Deviations for Five Acquisition and Two Extinction Indices

\begin{tabular}{|c|c|c|c|c|c|c|c|}
\hline \multirow[b]{3}{*}{ Groups } & \multicolumn{5}{|c|}{ Acquisition Indices } & \multicolumn{2}{|c|}{ Extinction Indices } \\
\hline & $(1)$ & $(2)$ & (3) & (4) & $(5)$ & (1) & $(2)$ \\
\hline & $\begin{array}{c}\text { Total } \\
\text { Trials }\end{array}$ & $\begin{array}{l}\text { Shock } \\
\text { Trials } \\
\end{array}$ & $\begin{array}{c}\text { Shock } \\
\text { Duration } \\
\text { (Sec) }\end{array}$ & $\begin{array}{c}\text { Trial } \\
\text { First CAR }\end{array}$ & $\begin{array}{c}\text { Latency First } 10 \\
\text { Consecutive } \\
\text { CARs (Sec) }\end{array}$ & $\begin{array}{c}\text { Total } \\
\text { Trials }\end{array}$ & $\begin{array}{c}\text { Latencies } \\
\text { (Sec) }\end{array}$ \\
\hline \multicolumn{8}{|c|}{ Experiment 1} \\
\hline $\mathrm{H}$ & $15.3 \pm 4.3$ & $4.0 \pm 1.8$ & $4.7 \pm 4.1$ & $3.8 \pm 1.9$ & $3.4 \pm 1.5$ & $45.5 \pm 28.2$ & $5.8 \pm 2.6$ \\
\hline NH & $13.2 \pm 2.6$ & $2.1 \pm 1.4$ & $3.6 \pm 1.9$ & $2.3 \pm 0.4$ & $2.8 \pm 1.5$ & $90.3 \pm 64.8$ & $2.1 \pm 0.7$ \\
\hline \multicolumn{8}{|c|}{ Experiment 2} \\
\hline $\mathrm{H}$ & $13.0 \pm 2.2$ & $2.0 \pm 1.0$ & $7.9 \pm 6.2$ & $2.6 \pm 0.9$ & $2.9 \pm 0.6$ & $35.6 \pm 17.5$ & $2.7 \pm 0.9$ \\
\hline NH & $16.2 \pm 5.0$ & $2.9 \pm 1.6$ & $5.9 \pm 4.8$ & $2.8 \pm 0.9$ & $2.9 \pm 0.9$ & $87.7 \pm 64.2$ & $3.3 \pm 2.3$ \\
\hline
\end{tabular}

Compartment $\mathrm{B}$, and placed on a table in front of the apparatus. A duplicate empty transport box was then inserted into Compartment B. Following this, the transport box holding $S$ was picked up and inserted into Compartment $A$. As the box touched the grid floor, the lug holding the floor in place was released, and the transport box was lifted out of the compartment. This maneuver gently slid $\mathrm{S}$ onto the grid floor. As $S$ in both groups touched the grid floor of Compartment A, $E$ engaged a manually operated microswitch which started the CS-US sequence.

\section{Results and Discussion}

One $S$ was discarded because of apparatus failure and one $S$ because $E$ experienced difficulty in handling the animal between trials. Both $\mathrm{Ss}$ were replaced on the next run. Groups were compared on five acquisition and two extinction indices. The acquisition indices analyzed were (1) number of training trials to acquisition criterion; (2) number of shock trials; (3) mean duration of shock received; (4) trial number of first CAR; and (5) response latencies for first 10 consecutive CARs. These indices were included mainly to provide the basis for a meaningful interpretation of the extinction data. Previous experience with the one-way avoidance apparatus indicated that, because of rapid learning obtained in this situation, differences in performance usually do not reflect themselves in this phase of the experiment. Table 1 (Experiment 1) provides the means and standard deviations of both groups for these indices. Statistically significant differences using a two-tailed test unexpectedly were obtained between Groups $\mathrm{H}$ and $\mathrm{NH}$ for Index $2(\mathrm{t}=2.9$, $\mathrm{df}=1 / 22, \mathrm{p}<.01)$ and Index $4(\mathrm{t}=2.5$, $\mathrm{df}=1 / 22, \mathrm{p}<.02)$. The $\mathrm{Ss}$ in Group NH received fewer shock trials and made their first CAR earlier than did Ss in Group $\mathrm{H}$. Indices 1 and 3 did not produce reliable differences. Analysis of variance over Index 5 did not produce a between-groups effect, but trials $(F=3.6, \mathrm{df}=9 / 198$, $\mathrm{p}<.01)$ and Trials by Groups interaction $(F=2.7, \quad \mathrm{df}=9 / 198, \quad \mathrm{p}<.01) \quad$ were significant. As the trials progressed, the latencies decreased for both groups. The interaction effect appeared to be due mainly to differences between the groups on Trial Blocks 1 and 3. Group $H$ produced reliably slower response latencies for these two blocks $(\mathrm{F}=9.4, \mathrm{df}=1 / 22, \mathrm{p}<.01$ $F=8.9, \mathrm{df}=1 / 22, p<.01)$. None of the remaining trial blocks even approached producing significant differences between groups.

The two extinction indices analyzed were (1) number of trials to extinction and (2) mean response latency for each $S$ during extinction. Index 1, which was expected to be the most sensitive, yielded a reliable difference between groups $(t=2.2$, $\mathrm{df}=1 / 22, \mathrm{p}<.05)$. As Table 1 indicates, the mean trials to extinction for Group NH is double the mean for Group H. For this index, only one $\mathrm{S}$ in Group $\mathrm{H}$ made more responses than the mean for Group $\mathrm{NH}$ and only three Ss responded more than the median. Index 2 also produced a statistical difference $(\mathrm{t}=3.8, \mathrm{df}=1 / 22, \mathrm{p}<.01)$, with the mean response latencies for Group $\mathrm{H}$ Ss being longer. Figure 2 provides a frequency distribution of the extinction latencies plotted in 1-sec class intervals for the first $15 \mathrm{sec}$. (Response latencies longer than $15 \mathrm{sec}$ accounted for less than $3 \%$ of the data.) The difference in distributions between groups is apparent and reflects the difference obtained for Index 2. For Group NH, the modal response occurred at $1 \mathrm{sec}$ ( $53 \%$ of the responses), with each successive class interval showing a progressive decrease in frequency. This is the usual finding obtained by us when the handling cage is employed or when a completely automated one-way avoidance apparatus is used. The response latencies for Group H Ss, however, peaked at $3 \mathrm{sec}$ (29\% of the responses) and produced a much more variable pattern of responding.

It is tempting to conclude from the above observations that between-trial handling of Ss retards performance. Indeed, the statistical differences reported support this conclusion. Nevertheless, it 


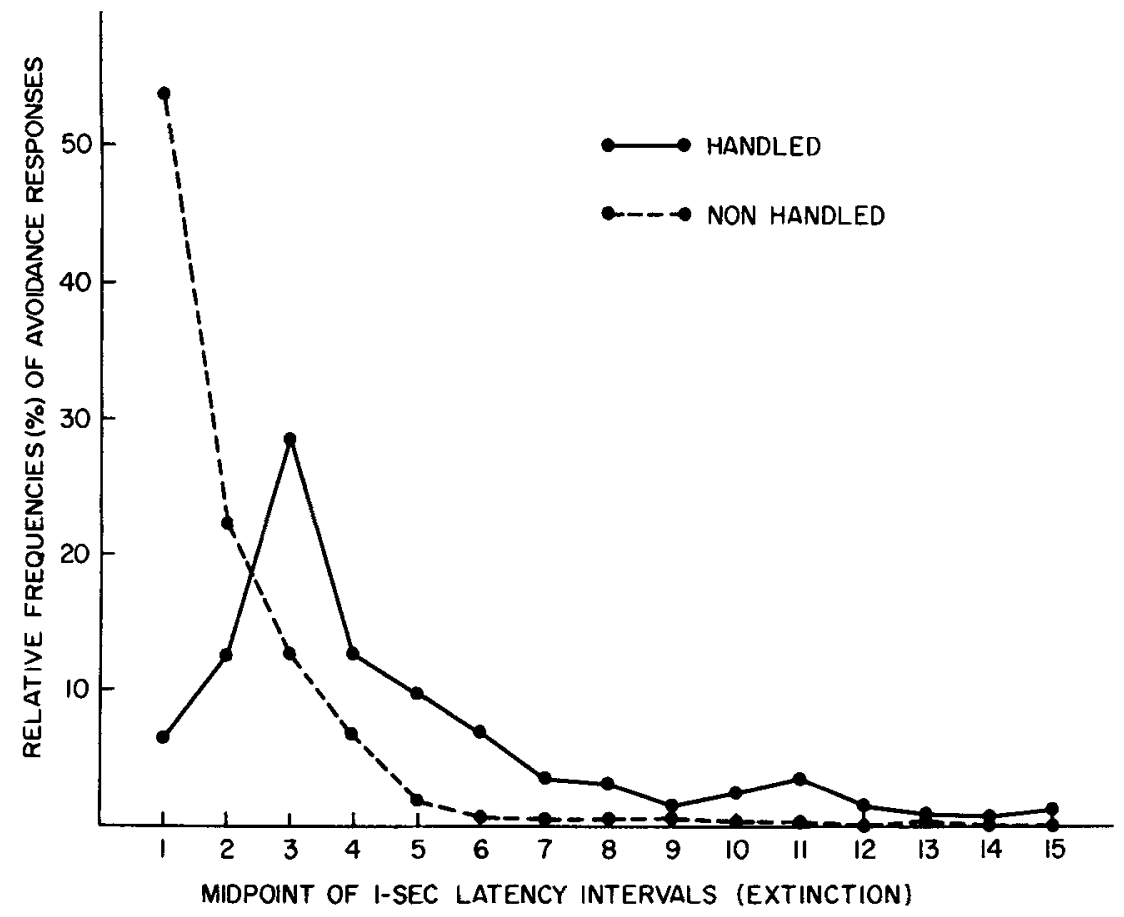

should be noted that the procedures of Groups $\mathbf{H}$ and $\mathrm{NH}$ differed in other respects than handling. For one thing, Group NH Ss' between-trial transport time averaged $6 \mathrm{sec}$ longer. (The mean transport times and standard deviations for Group $\mathrm{H}$ and Group NH were $7.1 \pm 2.1 \mathrm{sec}$ and $13.3 \pm 2.2 \mathrm{sec}$, respectively.) For another, Group H Ss were exposed to the same transport box throughout training which was not true for Group NH. Finally, it is possible that the force of placement on the grid as well as the complexity of the transport cues differed between groups.

\section{EXPERIMENT 2}

The present experiment was designed to determine whether the procedural differences other than handling between Groups $\mathrm{H}$ and $\mathrm{NH}$ noted in the discussion of the preceding experiment were responsible for producing the poorer performance of Group H Ss.

\section{Method}

Subjects and apparatus. The Ss were 24 experimentally naive male hooded rats bred in the University of Iowa's Department of Psychology colony. They ranged in age from 95 and 111 days. The apparatus was the same one described in Experiment 1.

\section{Procedure}

Twelve Ss were assigned randomly to one of two groups. Group NH followed the same procedure as Group NH in Experiment 1. Group $H$ procedure, however, was changed. In Experiment 1, Ss
Fig. 2. Frequency distribution of responses plotted for 1-sec latency intervals occurring during the extinction phase of Experiment 1.

double the mean for Group $H$. No Ss in Group $\mathrm{H}$ made more responses than the mean or the median for Group NH. Contrary to the findings of Experiment 1, statistical differences between the two groups were not obtained for the latency data recorded during extinction. The frequency distributions of the extinction latencies between groups also did not differ in shape with the modal response for both groups occurring to the first second of the CS-US interval. Fifty-five percent of the extinction responses occurred within $1 \mathrm{sec}$ for Ss in Group NH and $46 \%$ for Ss in Group H. It will be recalled that in Experiment 1 the modal response for Group $H$ occurred at the third second. The lack of a delay in responding by $S s$ in Group $\mathrm{H}$ noted in the present experiment may be related to the fact that Ss in this group were not handled immediately prior to the start of a trial, which was the case for $S s$ in the first experiment.

in Group $\mathrm{H}$ were transported between trials by being picked up by hand in Compartment $B$ and placed on the grid floor of Compartment $A$. In the present experiment, Ss in Group $\mathrm{H}$ were picked up by hand and lifted out of Compartment $B$. The transport box from Compartment $B$ was then removed and placed on a table in front of the apparatus. $S$ was replaced in the transport box. The duplicate empty transport box was then inserted into Compartment B. Following this, the transport box holding $S$ was picked up and inserted into Compartment $A$ in the manner outlined for Group NH in Experiment 1. Thus, Groups $\mathrm{H}$ and $\mathrm{NH}$ followed identical procedures except that $S$ was lifted out of Compartment B by hand instead of by the transport box. Transport times from Compartment B to $A$ for both Groups $\mathrm{H}$ and $\mathrm{NH}$ were equated. The handling time of $S s$ in this experiment was also approximately the same as for $\mathrm{Ss}$ in Experiment 1 .

\section{Results and Discussion}

Two Ss were discarded because of apparatus failure. They were replaced on the next run. Groups were compared on the same acquisition and extinction indices analyzed in Experiment 1. Table 1 (Experiment 2) provides the means and standard deviations for these indices. None of the acquisition indices differed between groups. As in Experiment 1, Group $\mathrm{H}$ differed reliably from Group NH in trials to extinction $(t=2.7, d f=1 / 22, p>.02)$. As Table 1 indicates, the mean trials to extinction for Group NH is more than

\section{CONCLUSIONS}

The consistency of the trials to extinction data between Experiments 1 and 2 supports the conclusion that the handling of $S$ between trials facilitates extinction of the one-way avoidance response. In fact, in the present experiments the rate was reduced by at least one-half in the handled groups.

Although it is conceivable that handling Ss between trials might not affect the conclusion reached about a given independent variable, the possibility still exists that handling could interact with the variable in question. Recently, Altman and Hommel (1969) provided data in an approach-avoidance conflict situation which support the hypothesis that handling produces a calming effect on $S$ within the context of an emotional or fear-producing situation. Such a result may well interact with a number of variables believed to affect avoidance performance. Furthermore, the handling of $S$ s both between and within experiments cannot be considered a standard entity, which provides another argument for its elimination.

The use of the transport box described in the present study appears to serve as an adequate and inexpensive substitute to handling. The use of the box should reduce the possibility of $\mathrm{E}$ bias as well as increase standardization in transporting Ss. It can be easily modified to accommodate maze and runway situations and does not require the pretest gentling of $S$. 
The basic concept of having $S$ terminate the response inside the transport box is believed an essential requirement in studies employing aversive stimulation. It has been our experience that handling devices that are lowered over $S$, like the one described by Tighe (1965), only seem to work well when applied to nonshock situations.

Whatever solution is devised, the procedure of handling Ss between trials is not only unnecessary but experimentally undesirable.

\section{REFERENCES}

ALTMAN, H. B., \& HOMMEL, L. S. The reduction of avoidance behavior as a function of gentling. Psychonomic Science, 1969, 14, 91-92.

BARRY, H., III. Habituation to handling as a factor in retention of maze performance in rats. Joumal of Comparative \& Physiological Psychology, 1957, 50, 366-367.

BERNSTEIN, L. Effects of variation in handling upon learning and retention. Journal of Comparative \& Physiological Psychology, $1957,50,162 \cdot 167$.

CANDLAND, D. K., FAULDS, B. D., THOMAS,
D. B., \& CANDLAND, M. H. The reinforcing value of gentling. Journal of Comparative \& Physiological Psychology, 1960, 53, 55-58.

CANDLAND, D. K., HOROWITZ, S. H., \& CULBERTSON, J. Acquisition and retention of acquired avoidance with gentling as reinforcement. Journal of Comparative \& Physiological Psychology, 1962, 55, 1062-1064.

CHRISTIE, R. Experimental naivete and experiential naivete. Psychological Bulletin, 1951, 4, 327-339.

MoCLELLAND, W. J. Differential handling and weight gain in the albino rat. Canadian Journal of Psychology, 1956, 10, 19-22.

SPERLING, S. E., \& VALLE, F. P. Handling-gentling as a positive secondary reinforcer. Journal of Experimental Psychology, 1964, 67, 573-576.

TIGHE, T. J. A handling device for small animals. Journal for the Experimental Analysis of Behavior, 1965, 8, 261-262.

WAHLSTEN, D., \& SHARP, D. Improvement of shuttle avoidance by handling during the intertrial interval. Joumal of Comparative \& Physiological Psychology, 1969, 67, 252-259.

WAHLSTEN, D., COLE, M., SHARP, D., \& FANTINO, E. Facilitation of bar-press avoidance by handling during the intertrial interval. Journal of Comparative \& Physiological Psychology, 1968, 65, 170-174.

WEININGER, $O$. The effects of early experience on behavior and growth characteristics. Journal of Comparative \& Physiological Psychology, 1956, 49, 1-9.

WEININGER, O., McCLELLAND, W. J., \& ARIMA, R. Gentling and weight gain in the albino rat. Canadian Journal of Psychology, $1954,8,147-151$.

\section{NOTE}

1. This investigation was supported in part by Biomedical Science Support Grant FR-07035 from the General Research Support Branch, Division of Research Resources, Bureau of Health Professions Education and Manpower Training, National Institutes of Health, and by Grant MH 16584-01 from the National Institute of Mental Health. The author also wishes to express his gratitude to Kathi Singerman for her assistance in the collection of data and to Judson S. Brown for reading a draft of the manuscript and contributing to the design of Experiment 2 . The initial conception and construction of the transport box was developed when the author was at the Laboratory of Psychobiology, Lafayette Clinic, Detroit, Michigan.

\section{Probability gate statistics}

\author{
JAMES N. CRONHOLM, U.S. ARMY \\ MEDICAL RESEARCH LABORATORY, \\ Fort Knox, Kentucky 40121
}

A probability gate presents a fixed but controllable transmission probability $p$ to pulses arriving at its input. This paper describes some statistical properties of the transformation imposed by a gate on the input distribution of interpulse intervals. The output distribution of interpulse intervals is derived in terms of the input density and $p$. A simple relation is shown to hold between the moment generating functions, and the first four output moments are presented in terms of the input moments and p. Certain restrictions on the kinds of obtainable output distributions are discussed. In particular, a condition is established that specifies when the output density is a "replica" of the input distribution.

Aside from their roles as conceptual units in models of processes in such diverse areas as traffic flow (Haight, 1963) and signal detection (Luce, 1966), probability gates are used most frequently to increase the means of given, but usually unspecified, distributions of interevent intervals. For example, if a pulse train representing the responses of a rat in a
Skinner box is applied to the input of a probability gate and its output pulse train actuates a source of reinforcements, then, when the transmission probability is set to $\mathrm{p}$, the probability that the rat will be reinforced for any response is just $p$. The reciprocal of the means of the input and output distributions of interpulse intervals, i.e., the response and reinforcement rates, are typically monitored during experiments using variable-ratio reinforcement schedules, and it is readily seen that reinforcement rate is given by $p$ times the response rate.

The purpose of this note is to show how the temporal input and output probability distributions, their moment-generating functions (MGFs), and, hence, their moments are related in general. The results presented impose certain limitations on the kinds of output distributions that can be instrumented.

In the following derivations, the pulses referred to will be idealized as points, and a probability gate will be regarded as a device which at any moment presents a fixed transmission probability $p$ to pulses arriving at its input. In addition, it will be assumed that the MGFs referred to exist.

First, the output probability density of interpulse intervals, say $y(t)$, will be obtained as a function of the input distribution, say $u(t), 0<t$, and $p$. If a pulse has just appeared at the output, the probability that the next $n-1$ input pulses will be rejected while the $n^{\text {th }}$ pulse is transmitted is given by the geometric distribution:

$w(n)=p q^{n-1}, q=1-p, n=1,2,3, \cdots$.

The time between the initially transmitted pulse and the $\mathrm{n}^{\text {th }}$ input pulse following it is the sum of $n$ independent interpulse intervals, each of which is distributed as $u(t)$. The probability, conditional on $n$, that the total interval is $t$ sec in duration is thus given by the $\mathrm{n}$-fold convolution of $u(t)$ with itself:

$$
v(t \mid n)=u(t)^{* n} .
$$

The joint density of $t$ and $n$ is the product of $v(t \mid n)$ and $w(n)$, and summing this over all values of $n$ gives the required distribution of output interpulse intervals as a function of the input distribution and p. Thus, all output distributions have the form:

$$
y(t)=\sum_{n=1}^{\infty} u(t)^{* n} p q^{n-1}, 0<t
$$

A special case of this derivation has been used to show that if $u(t)$ is exponential with its origin at 0 and time constant $\beta$, then $y(t)$ is also exponential, but with time constant $p \beta$ (Cronholm, 1969).

A very simple relation exists between the MGFs of the input and output distributions. Using this, the moments of 